\title{
Evarcha culicivora chooses blood-fed Anopheles mosquitoes but other East African jumping spiders do not
}

\author{
R. R. J A C K S O N ${ }^{1,2}$ and X. J. NEL S O N
}

${ }^{1}$ Department of Xxx, School of Biological Sciences, University of Canterbury, Christchurch, New Zealand and ${ }^{2}$ Department of Xxx, International Centre of Insect Physiology and Ecology, Mbita Point, Kenya

\begin{abstract}
Previous research using computer animation and lures made from dead prey has demonstrated that the East African salticid Evarcha culicivora Wesolowska \& Jackson (Araneae: Salticidae) feeds indirectly on vertebrate blood by actively choosing blood-carrying female mosquitoes as prey, and also that it singles out mosquitoes of the genus Anopheles (Diptera: Culicidae) by preference. Here, we demonstrate that E. culicivora's preference is expressed when the species is tested with living prey and that it is unique to E. culicivora. As an alternative hypothesis, we considered the possibility that the preference for blood-fed female anopheline mosquitoes might be widespread in East African salticids. When live-prey choice tests were carried out in 19 additional species, there were no instances in which blood-carrying mosquitoes were chosen significantly more often than other prey. Combined with the findings of previous work, these results suggest that it is possible that specialized predators play a role in the biological control of disease vectors.
\end{abstract}

Key words. Anopheles gambiae, Evarcha culicivora, foraging, mosquitoes, predation, prey preferences, specialization.
Because they have intricate, vision-guided prey-capture behaviour (Jackson \& Pollard, 1996) and the ability to see fine detail (Harland et al., 2011), jumping spiders (Salticidae) are especially suitable subjects in experiments on prey-choice behaviour (Nelson \& Jackson, 2011). There are numerous examples of salticids expressing distinctive preferences for other spiders or for ants (Jackson \& Pollard, 1996). However, it may be that the East African salticid Evarcha culicivora Wesolowska \& Jackson, the natural prey of which consists mainly of mosquitoes (Wesolowska \& Jackson, 2003), illustrates the most unexpected precision in prey-choice behaviour. This is a spider that feeds indirectly on vertebrate blood by actively choosing blood-fed female mosquitoes as prey (Jackson et al., 2005), and it also expresses a preference for Anopheles (Nelson \& Jackson, 2006), the mosquito genus to which all human malaria vectors belong (Clements, 1999).

Experiments based on using motionless lures and/or virtual prey generated by computer animation have demonstrated that
E. culicivora makes fine discriminations between anopheline and less preferred culicine mosquitoes, even when it is restricted to visual cues alone (Jackson et al., 2005; Nelson \& Jackson, 2006). Filling an important gap left by earlier work, we confirm that E. culicivora makes prey-choice decisions that deliver bloodmeals when living prey are used in experiments. We also consider an alternative to our hypothesis that E. culicivora's specialized preferences are unique or at least exceedingly unusual. The alternative hypothesis is that preference for blood-carrying mosquitoes is widespread in East African salticids. We addressed this hypothesis by undertaking identical experiments using another 19 East African salticid species.

All testing was carried out between 08.00 hours and 19.00 hours (in a laboratory photoperiod of LD $12: 12 \mathrm{~h}$, with lights on at 07.00 hours) using spiders that had been starved for 7 days prior to testing. All test spiders (always $n>20$ ) were adult females that had matured in laboratory culture $2-3$ weeks

Correspondence: Ximena J. Nelson, Department of Xxx, School of Biological Sciences, University of Canterbury, Private Bag 4800, Christchurch 8081, New Zealand. Tel.: +64 33642987 (ext. 4050); Fax: +64 3364 2590; E-mail: ximena.nelson@canterbury.ac.nz 
Table 1. Simultaneous-presentation tests of female salticids (Araneae: Salticidae).

\begin{tabular}{|c|c|c|c|c|}
\hline Salticid species & Prey $2 \dagger$ & Chose prey $1^{*}, n$ & Chose prey $2 \dagger, n$ & $\chi^{2}$ \\
\hline \multirow[t]{2}{*}{ Evarcha culicivora } & C. claripennis & 20 & 5 & 9.000 . \\
\hline & An. gambiae, $\mathrm{M}$ & 18 & 2 & $12.800 \S$ \\
\hline \multirow[t]{2}{*}{ Asemonea murphyae Wanless } & C. claripennis & 12 & 15 & 0.333 \\
\hline & An. gambiae, $\mathrm{M}$ & 15 & 15 & 0.000 \\
\hline \multirow[t]{2}{*}{ Cyrba ocellata (Kroneberg) } & C. claripennis & 14 & 14 & 0.000 \\
\hline & An. gambiae, $\mathrm{M}$ & 13 & 13 & 0.000 \\
\hline \multirow[t]{2}{*}{ Goleba puella (Simon) } & C. claripennis & 18 & 14 & 0.500 \\
\hline & An. gambiae, $\mathrm{M}$ & 17 & 17 & 0.000 \\
\hline \multirow[t]{2}{*}{ Harmochirus brachiatus (Thorell) } & C. claripennis & 20 & 14 & 1.059 \\
\hline & An. gambiae, $\mathrm{M}$ & 15 & 16 & 0.032 \\
\hline \multirow[t]{2}{*}{ Hasarius adansoni (Savigny \& Audouin) } & C. claripennis & 16 & 16 & 0.000 \\
\hline & An. gambiae, $\mathrm{M}$ & 15 & 18 & 0.273 \\
\hline \multirow{2}{*}{ Holcolaetis vellerea (Simon) } & C. claripennis & 17 & 18 & 0.000 \\
\hline & An. gambiae, $\mathrm{M}$ & 14 & 16 & 0.133 \\
\hline \multirow[t]{2}{*}{ Hyllus sp. } & C. claripennis & 12 & 15 & 0.333 \\
\hline & An. gambiae, $\mathrm{M}$ & 18 & 15 & 0.273 \\
\hline \multirow[t]{2}{*}{ Meleon solitaria } & C. claripennis & 19 & 15 & 0.471 \\
\hline & An. gambiae, $\mathrm{M}$ & 16 & 17 & 0.030 \\
\hline \multirow[t]{2}{*}{ Menemerus bivittatus (Dufour) } & C. claripennis & 14 & 16 & 0.133 \\
\hline & An. gambiae, $\mathrm{M}$ & 17 & & 0.029 \\
\hline \multirow[t]{2}{*}{ Menemerus congoensis Lessert } & C. claripennis & 16 & 16 & 0.000 \\
\hline & An. gambiae, $\mathrm{M}$ & 14 & 15 & 0.034 \\
\hline \multirow[t]{2}{*}{ Menemerus sp. } & C. claripennis & 19 & 13 & 1.125 \\
\hline & An. gambiae, $\mathrm{M}$ & 16 & 16 & 0.000 \\
\hline \multirow[t]{2}{*}{ Myrmarachne melanotarsa Wesolowska \& Salm } & C. claripennis & 14 & 13 & 0.037 \\
\hline & An. gambiae, $\mathrm{M}$ & 15 & 12 & 0.333 \\
\hline \multirow[t]{2}{*}{ Natta rufopicta (Simon) } & C. claripennis & 16 & 11 & 0.926 \\
\hline & An. gambiae, $\mathrm{M}$ & 15 & 15 & 0.000 \\
\hline \multirow[t]{2}{*}{ Pachyballus cordiformis Berland \& Millot } & C. claripennis & 13 & 15 & 0.143 \\
\hline & An. gambiae, $\mathrm{M}$ & 13 & 15 & 0.143 \\
\hline \multirow[t]{2}{*}{ Parajotus cinereus Wesolowska } & C. claripennis & 18 & 15 & 0.273 \\
\hline & An. gambiae, $\mathrm{M}$ & 19 & 16 & 0.257 \\
\hline \multirow[t]{2}{*}{ Plexippus sp. } & C. claripennis & 19 & 15 & 0.471 \\
\hline & An. gambiae, $\mathrm{M}$ & 19 & 15 & 0.471 \\
\hline \multirow[t]{2}{*}{ Portia africana } & C. claripennis & 14 & 16 & 0.133 \\
\hline & An. gambiae, $\mathrm{M}$ & 18 & 14 & 0.500 \\
\hline \multirow[t]{2}{*}{ Pseudicius sp. (Simon) } & C. claripennis & 15 & 10 & 1.000 \\
\hline & An. gambiae, $\mathrm{M}$ & 15 & 15 & 0.000 \\
\hline \multirow[t]{2}{*}{ Thyene sp. } & C. claripennis & 16 & 16 & 0.000 \\
\hline & An. gambiae, $\mathrm{M}$ & 15 & 20 & 0.714 \\
\hline
\end{tabular}

*Prey 1: blood-fed Anopheles gambiae, female.

$\dagger$ Prey 2: Clinotanypus claripennis (male or female) or Anopheles gambiae, male (M).

$\chi^{2}$ tests of goodness of fit: $¥ P<0.01 ; \S P<0.001$; all other rows $P>0.05$.

before being used. Spiders were housed individually in spacious cages enriched with a meshwork of twigs. Spiders were reared on a mixed diet of non-biting midges collected locally, as well as on male and female mosquitoes (spiders were given unlimited access to all prey types three times per week). Mosquitoes used for rearing were Anopheles gambiae s.s. Giles from laboratory culture (Jackson et al., 2005). In culture, all mosquitoes had continuous access to glucose ( $6 \%$ solution) and only sugar-fed mosquitoes were used as maintenance prey for the spider cultures. The expression 'blood-fed' refers to female mosquitoes that had received a bloodmeal (from a human host) $4 \mathrm{~h}$ before being used in a prey-choice test.

During prey-choice testing, one prey was always a bloodfed An. gambiae female. The other prey was either a male or a male or female midge [Clinotanypus claripennis Kieffer (Diptera: Chironomidae)]. All prey were $5.0 \mathrm{~mm}$ in body length (accurate to the nearest $0.5 \mathrm{~mm}$ ). Tests were carried out in a glass arena $(100 \times 100 \times 35 \mathrm{~mm})$, with a removable glass lid $(100 \times 100 \mathrm{~mm})$. A hole (diameter $16 \mathrm{~mm})$ in the centre of the floor, situated $10 \mathrm{~mm}$ from one end of the box and plugged with a removable rubber bung, was used to introduce prey and the test spider into the arena. To begin testing, a test spider was allowed to enter through the hole once two live prey were in the arena. Trials ended when the salticid captured and began feeding on one of the two prey items.

When E. culicivora was used in the prey-choice tests, significantly more test spiders chose blood-fed mosquitoes than the alternative prey (Table 1). However, when the other 
19 salticid species were tested, the number of test spiders that chose blood-fed mosquitoes did not differ significantly from the number that chose the alternative prey, although all methods were identical to those used with E. culicivora and the sample size was always equal to or larger than that used when testing E. culicivora. These findings confirm that E. culicivora expresses prey-choice behaviour with living prey comparable with that shown earlier with lures and virtual prey, and provide no support for the hypothesis that choosing among blood-fed mosquitoes is widespread in East African salticids. Combined with the findings of previous work (Wesolowska \& Jackson, 2003; Jackson et al., 2005; Nelson \& Jackson, 2006), these results suggest that the notion that specialized predators have a role in the biological control of disease vectors may be a realistic possibility.

\section{Acknowledgements}

We thank Godfrey Otieno Sune, Stephen Abok Aluoch, Silas Ouko Orima and Jane Atieno Obanyo for technical assistance at the International Centre of Insect Physiology and Ecology. This research was supported by the Royal Society of New Zealand, the National Geographic Society and the National Institutes of Health.

\section{References}

Beadle, L.C. (1981) The Inland Waters of Tropical Africa: An Introduction to Tropical Limnology. Longman, London.

Harland, D.P., Li, D. \& Jackson, R.R. (2011) How jumping spiders see the world. How Animals See the World: Behavior, Biology, and Evolution of Vision (ed. by O. Lazareva, T. Shimizu \& E. Wasserman), pp. xxx-xxx. Oxford University Press, Oxford.

Jackson, R.R. \& Pollard, S.D. (1996) Predatory behaviour of jumping spiders. Annual Review of Entomology, 41, 287-308.

Jackson, R.R., Nelson, X.J. \& Sune, G.O. (2005) A spider that feeds indirectly on vertebrate blood by choosing female mosquitoes as prey. Proceedings of the National Academy of Science of the United States of America, 102, 15155-15160.

Nelson, X.J. \& Jackson, R.R. (2006) A predator from East Africa that chooses malaria vectors as preferred prey. PLoS One, 1, e132.

Nelson, X.J. \& Jackson, R.R. (2011) Flexibility in the foraging strategies of spiders. Spider Behaviour: Flexibility and Versatility (ed. by M.E. Herberstein), pp. xxx-xxx. Cambridge University Press, New York, NY.

Wesolowska, W. \& Jackson, R.R. (2003) Evarcha culicivora sp nov., a mosquito-eating jumping spider from East Africa (Araneae: Salticidae). Annales Zoologici, 53, 335-338.

Accepted dd Month 2011

(C) 2011 The Authors

Medical and Veterinary Entomology (c) 2011 The Royal Entomological Society, Medical and Veterinary Entomology, 0, 0-0 
QUERIES TO BE ANSWERED BY AUTHOR

IMPORTANT NOTE: Please mark your corrections and answers to these queries directly onto the proof at the relevant place. DO NOT mark your corrections on this query sheet.

\section{Queries from the Copyeditor:}

AQ1. Insert name of department.

AQ2. Insert name of department.

AQ3. Order: Family has been inserted; please check.

AQ4. Order: Family has been inserted; please check.

AQ5. 2011 inserted for Harland et al.; please check.

AQ6. Clements, 1999 has not been included in the Reference List, please supply full publication details.

AQ7. Insert name of department.

AQ8. Order: Family has been inserted; please check.

AQ9. 'An. gambiae or a male or' inserted; please check.

AQ10. Beadle, 1981 has not been cited in the text. Please indicate where it should be cited; or delete from the Reference List.

AQ11. 2011 inserted for Harland et al.; please check (if this reference has not yet been published; please delete from the reference list and insert as 'unpublished material' in the text.

AQ12. Insert page range for this chapter.

AQ13. Insert page range for this chapter.

AQ14. Insert accepted date. 